\title{
Los intelectuales ante la República
}

\author{
Genoveva García QueIPo de Llano
}

La presente ponencia constituye la lógica prolongación de mi libro sobre los intelectuales y la Dictadura del general Primo de Rivera, publicado en 1988 por Alianza Editorial y complementada con algunos trabajos monográficos accesorios. Como continuación de los mismos he seguido investigando y tengo en preparación un libro que versa sobre las posiciones del mundo intelectual durante el corto período que va desde febrero de 1930 hasta abril de 1931, en el momento de la proclamación de la Segunda República. En mi ponencia voy a procurar exponer algunas de sus conclusiones más importantes. Me parece indudable que esos meses son decisivos desde el punto de vista de la intervención de los intelectuales españoles en la política. En efecto, en ellos no sólo adquirieron una decidida beligerancia pro-republicana sino que esbozaron el conjunto de las posturas que les caracterizarían a lo largo de los años treinta. Por otro lado nunca su intervención en la vida pública fue tan decisiva como en estos instantes. Ellos contribuyeron de forma importante a la proclamación del nuevo régimen pero a partir de esa fecha, además, dejaron de ser la vanguardia política del momento para desempeñar un papel considerablemente más modesto. En última instancia, bien puede decirse que durante la guerra civil no hicieron otra cosa que llevar hasta sus últimas consecuencias el compromiso adquirido en esos meses.

En una intervención ante un auditorio de especialistas, como es lógico, voy a dar por conocido en sus líneas generales todo el proceso que lleva a la toma de postura de los intelectuales en sentido republicano. Procuraré insistir, además, en aquellos aspectos que me parecen más novedosos de mi investigación.

Debo sin embargo, hacer una brevísima alusión a la etapa dictatorial que no será sino el resumen del libro que he citado con anterioridad. Cuando se produjo el pronunciamiento de Primo de Rivera no todo el mundo intelectual estuvo en su contra sino que más bien la mayoría adoptó una postura de benevolente espectativa, más por oposición al régimen caído que por un autoritarismo de fondo. La fecha decisiva en la historia 
de las relaciones entre el Dictador y los intelectuales fue 1926. Ya entonces Unamuno estaba exiliado y también Azaña se había distinguido en la oposición a su régimen. En dicho año el Dictador comenzó a enfrentarse de modo sistemático con los intelectuales. Sin embargo, los años 1927 y 1928 transcurrieron entra la «pureza» y la politización. En este último año se producen cambios tan significativos como la sustitución de la poesía pura por la novela social, o el abandono por parte de Ortega de su posición de mentor del General. La rebelión de los estudiantes en 1929 proporcionó a la oposición intelectual un procedimiento para estar presente en la calle. Durante la Dictadura se confirmó el autoritarismo de Maeztu y D'Ors y el concepto «militante y docente" de la democracia que había sido acuñado por Azaña. Sin embargo, a comienzos de 1930 ni la República parecía próxima ni los intelectuales estaban de manera unánime a su favor. Ambos procesos tuvieron lugar en los dieciséis meses que transcurren desde la caída del Dictador al advenimiento del nuevo régimen.

Durante ellos, de manera rapidísima, los intelectuales llevaron a sus últimas consecuencias las posturas anteriores. Sin duda las peculiaridades de los gobiernos de Berenguer y Aznar contribuyen a explicar esa rápida conversión al republicanismo: el Gobierno tenía conciencia de no ser legítimo y aseguraba que volvería a la legalidad constitucional, pero lo hizo con una extremada lentitud que provocó la lógica impaciencia de los intelectuales. El paso del tiempo influyó de modo decisivo sobre ellos. La mejor prueba es que la conversión de Ortega y "Azorín" al republicanismo se produjo en una fecha tardía, a fines de 1930. Resulta, por tanto, preciso dividir la etapa que aquí voy a abordar en otros dos períodos que denominaré, respectivamente, «Hacia el cambio» y «Por la República».

\section{«HACIA EL CAMBIO»}

Se puede considerar que de modo aproximado la fecha de separación entre los dos períodos es octubre de 1930. Durante la primera etapa lo esencial es la decantación de las posiciones asumidas por los intelectuales durante el período dictatorial, pero sin un sustancial incremento de las filas del republicanismo en estos medios culturales.

Llama la atención, en primer lugar, el relevo que se produce en estos momentos en el protagonismo en la beligerancia política de los intelectuales. Don Miguel de Unamuno había sido el símbolo viviente de la oposición en contra del Directorio militar y su regreso a España, nada más concluido el régimen de Primo de Rivera, fue el "retorno" de un emblema antidictatorial. Sin embargo, Unamuno se pronunció muy poco en términos 
estrictamente políticos, y sí de antagonismo personal con el Dictador y el Rey, utilizando palabras durísimas, incluso tremendas. En cambio, a lo largo de sus intervenciones se pudo apreciar muy poca política partidista en estrictos términos. Repetidamente practicó lo que él mismo denominaba como "paradojismo" y de modo explícito se negó radicalmente a presidir o a inspirar cualquier acción colectiva de los intelectuales. En el fondo le preocupaban mucho más otras cosas, como por ejemplo, embestir contra el "catolicismo santiagueño", es decir, el de Santiago Matamoros o la alianza entre la religión y la espada. Por si fuera poco, a la altura de mayo de 1930 , desapareció prácticamente de la vida pública nacional cuando tenía el apoyo entusiasta de todas las generaciones intelectuales en el caso de que se hubiera volcado a la acción. Aunque Unamuno siguió teniendo una actuación política nunca alcanzó la relevancia que había tenido en la etapa dictatorial. Durante ella predominó mucho más la voluntad destructiva del régimen primorriverista que la enunciación de un programa político propiamente dicho.

Otros dos personajes de la generación finisecular habían estado contra la Dictadura eligiendo como símbolo de su lucha al catedrático de Salamanca. La oposición de Valle Inclán había sido ostentosa, con los mismos ribetes de enfrentamiento personal con el Dictador que la de Unamuno; la de Machado fue entusiasta pero callada. La obra de Valle Inclán puede considerarse prácticamente agotada a la altura de 1930, aunque la que planeó Los cucos del Pardo o las modificaciones que introdujo en la ya escrita testimonian su repudio del régimen de la Restauración. Sin embargo fue mucho más antiprimorriverista que prorrepublicano, e incluso puede atribuírsele como a Unamuno una cierta posición irónica respecto del cambio de régimen. Machado, gran entusiasta de Unamuno, sólo acabó en una iniciativa orteguiana como la "Agrupación al servicio de la República" por la automarginación del catedrático de Salamanca.

Otro rasgo de la primera parte de 1930 es la continuación del proceso de radicalización en buena parte del mundo intelectual iniciado en los años anteriores y que afectó tanto a jóvenes como a miembros de generaciones anteriores. Ya en el año 1928 "Azorín" estaba muy lejos de su inicial colaboracionismo con la Dictadura y había elegido como mentor a Unamuno. Desde comienzos de 1930 se aprecia en sus artículos, con la vaguedad y levedad que en él siempre fueron características, una creciente preocupación política y social. Así se demuestra en sus comentarios acerca de los libros políticos del momento, en sus evocaciones en torno a la tradición liberal española (incluyendo en ella a algún presidente republicano como Castelar) o en la aparición de alusiones a la desigualdad social padecida en España. Se puede decir, incluso, que la voluntad «azo- 
riniana» de mostrar su cambio político queda testimoniada por sus elogios constantes a la nueva generación intelectual del momento.

Fue en el mundo juvenil donde resultó más perceptible la evolución política en sentido izquierdista. Lo que Jiménez de Asúa denominó como "generación de 1929" se hizo presente de manera pública, precisamente, en estos momentos. De ellos data la aparición del libro de Díaz Fernández titulado El nuevo romanticismo en que se propugna, frente al arte de vanguardia, la llamada "literatura de avanzada», es decir la que se basa en un compromiso político y social radical.

El radicalismo político de los más jóvenes pudo percibirse en manifestaciones muy variadas. El diario El Sol publicó una sección titulada «El estudiante de acción" que informó periódicamente sobre la agitación política de los universitarios que duraría hasta el cambio de régimen. Mucho más significativo es el cambio que se produce en estos momentos en $\mathrm{La}$ Gaceta Literaria que, dirigida por Ernesto Giménez Caballero, había sido la principal propugnadora del vanguardismo formal en otros tiempos. En las páginas de esta revista es perceptible, casi día a día, la crecida del interés por la política que hizo que, por ejemplo, un César María de Arconada, después de haber abominado de la preocupación por la política se entregara apasionadamente a ella. No es, ni mucho menos, el único caso sino que constituye un fenómeno de carácter mucho más general. Giménez Caballero llegaría a decir, en estas fechas, que si en el pasado a los jóvenes les "repugnaba" la política, ahora "la paladean y la degluten desenfrenadamente».

De todas las maneras los mejores testimonios de la politización juvenil se aprecian no en La Gaceta Literaria sino en tres revistas extremadamente politizadas aparecidas en los primeros meses de 1930: Política, Nueva España y Nosotros. Estas publicaciones nos ponen en contacto con la realidad de que esa radicalización juvenil no se detuvo en las fórmulas liberales o republicanas, sino que acabó por identificarse con la extrema izquierda. Nueva España, por ejemplo, mantuvo una posición claramente prosoviética.

De todos los modos al enjuiciar lo sucedido con esta joven generación intelectual hay que tener en cuenta que ni la politización fue necesariamente inmediata, ni tuvo un único sentido. El caso de Alberti es en este sentido muy significativo: su rebeldía fue estética y de talante vital hasta el momento mismo de la proclamación del régimen republicano. Por otro lado, había quienes en un momento muy anterior ya expresaban, una postura de radical oposición al sistema político vigente, pero sin que eso quisiera decir que defendieran unas opciones políticas concretas: tal es el caso de Moreno Villa. Finalmente, no se ha de olvidar que si la mayor 
parte de los jóvenes evolucionaron hacia la extrema izquierda también hubo quienes optaron por la extrema derecha. Cuando Sánchez Mazas o Ledesma Ramos hablaban de los "nuevos panoramas" o de los "mitos" de la contemporaneidad lo hacian para identificarse con el fascismo.

El intelectual que tanto durante esta época como en las anteriores consiguió agrupar tras de sí a un número más considerable de miembros de los medios culturales fue, sin duda, José Ortega y Gasset, por lo que reviste un especial interés hacer alusión a su postura. En el mes de marzo de 1930 tuvo lugar una primera actuación conjunta de los sectores intelectuales con ocasión de la visita a Barcelona de un grupo de ellos que se habian significado, especialmente, por la defensa de la lengua catalana en la época dictatorial. Sin embargo, ni Ortega había sugerido este acto ni se puede decir que lo presidiera aunque desempeñó en él un papel relevante. De todos los modos hizo en esta ocasión Ortega una afirmación que preside toda su actuación en estos momentos. Para él la vida española necesitaba «un reforma radical»; este fue el motivo principal de su actuación en los meses siguientes.

Ortega estaba en estos momentos en la etapa de su plenitud vital no sólo desde el punto de vista filosófico sino también desde la perspectiva de su relevancia en la vida pública nacional. Creía que había llegado el momento de que un estado liberal y modernizador se construyera en España: a eso llamó en estos momentos la «nacionalización» de las instituciones públicas. Frente a lo que acabaría siendo su postura, Ortega mostró una confianza inicial indudable por el Gobierno Berenguer, al que consideró dotado de esa "decencia jurídica" de la que había carecido Primo de Rivera. Además dudó sobre su capacidad de actuación partidista en la política. Sus ideas básicas sobre el porvenir eran, sin embargo, perfectamente claras: La Rebelión de las masas fue escrita desde una óptica liberal que excluía al comunismo y al fascismo.

Sólo a la vuelta del verano del año 1930 y después de haber dudado considerablemente, Ortega se proclamó republicano. Lo hizo en sus conferencias sobre la "Misión de la Universidad", partiendo de la responsabilidad del intelectual en la vida pública. Pero su proclamación resultó mucho más resonante cuando, en el mes de noviembre, apareció su artículo «El error Berenguer». Lo importante del mismo es que en él demostraba haber llegado a la conclusión de que la monarquía era incapaz de llevar a cabo ese proceso de «nacionalización» del Estado; por el contrario su existencia tenía como fundamento único «especular con los vicios nacionales". Interesa sobre todo recalcar que la postura de Ortega, siendo republicana, tenía unos perfiles diferenciadores precisos: no era ni el antiprimorriverismo de la generación de Unamuno ni el radicalismo juvenil. 
Partía de la base de propugnar para España un Estado liberal y modernizador que sólo podía ser republicano.

Como veremos, la posición de Ortega adquiriría en el futuro nuevos perfiles, a los que se hará mención más adelante. Nos queda sin embargo, aludir a quienes antes de concluir 1930, en esta primera etapa, habían ya adquirido una postura que no variaría con posterioridad.

Este es el caso, por ejemplo, de Azaña, del que me ha resultado posible encontrar varios inéditos que confirman una continuidad absoluta entre su posición de 1925 y las sucesivas actitudes que fue adoptando. En estos meses Azaña ofreció una imagen a la vez de radicalismo y de capacidad práctica. El primero se apreció en su repudio a que unas futuras instituciones republicanas estuvieran dispuestas a "gobernar con los moderados", tal como propugnaban Lerroux y Alcalá Zamora. La moderación era para él un enemigo capaz de destruir los ideales republicanos, ese "fanatismo por la idea» del que hizo gala en más de una ocasión. Pero, por otro lado, frente al republicanismo del pasado Azaña demostró su capacidad para la acción práctica a través de su gestión en el Ateneo. Toda ella estuvo dirigida a lograr el responsabilismo antidictatorial y a "dar cabida a lo proscrito" durante la etapa de gobierno anterior. Para completar el talante del Azaña de estos momentos es preciso recalcar que en él se daba una conciencia de responsabilidad generacional muy acusada y, sin duda, parecida a la de Ortega. El contenido de la acción política a desarrollar era, sin embargo, muy distinto: la cinteligencia como empresa demoledora" de Azaña era el precedente de su actitud en el período de gobierno 1931-1933, aunque se sintiera como Ortega en la "madurez frutuosa del otoño vital». Por supuesto esa conciencia generacional resulta sobre todo perceptible en su Discurso de noviembre de 1930 acerca de "Tres generaciones en el Ateneo".

En la generación de 1914 hubo quienes no se contentaron con un radicalismo puramente republicano sino que evolucionaron hacia posturas socialistas. En el caso de Gregorio Marañón esta actitud estuvo provocada por su oposición a la Dictadura en la última fase de la misma y resultó muy poco duradera. En cambio fue mucho más consistente y perdurable en Araquistain y en Jiménez de Asúa. El primero reingresó en el socialismo en 1929. Su libro El ocaso de un régimen partía de la consideración de que era necesaria una revolución transformadora del Estado en lo que él denominaba un "Estado público», en donde no sólo habría una transformación política de las instituciones sino también otra de carácter económico y social, gracias a la cual la República sería capaz de hacer desaparecer los vicios nacionales. Jiménez de Asúa, especialmente preocupado de temas juveniles, se declaraba a estas alturas «republicano al 
servicio del socialismo", pero sin haber llegado a una definitiva adscripción política.

\section{«POR LA REPUBLICA»}

Como ya se ha señalado, aunque hubiera intelectuales cuya conversión al republicanismo fuera muy anterior, sólo a finales de 1930 se produjo un decantamiento en este sentido de otros cuyas posiciones habian sido diferentes. Es muy significativa la fecha de el artículo orteguiano «El error Berenguern.

Ya antes «Azorín» se había declarado republicano. En octubre de 1930 abandonó $A B C$ y en adelante se describió a sí mismo como federal. Como en él era habitual, más que profundizar en este género de doctrinas lo que hizo fue evocar a quienes en el pasado las habían proclamado, como era el caso de $\mathrm{Pi}$ i Margall. Sus colaboraciones en la prensa, ahora en El Sol (y luego en Crisol) o en Argentina demuestran una influencia muy evidente del ambiente sociopolítico de la España del momento. Constantemente se refiere a la colaboración entre obreros e intelectuales, o a la necesidad de romper con los prejuicios que dan una visión demasiado revolucionaria de las instituciones republicanas. Merece la pena citar la contraposición entre dos artículos suyos en el momento mismo de la transición de régimen. En uno presenta a un supuesto rey, llamado Othon XII, que acepta las instituciones republicanas como testimonio de progreso; en otro artículo titulado "Cuento de niños" aparece en el infierno un monarca español que resulta ser Fernando VII. Para "Azorín», sin duda, Alfonso XIII estaba más cercano de este último caso que del primero.

Las iniciativas colectivas más importantes del mundo intelectual y aquellas de las que ha perdurado obviamente una memoria histórica son las que tuvieron como protagonista fundamental a Ortega. Su capacidad de promoverlas confirma esa sensación de madurez vital y de conciencia del relevante papel que debía corresponderle; pero no en todas las ocasiones Ortega se vio acompañado por el éxito. En el mes de diciembre de 1930, en un artículo periodístico, presentó como proyecto propio la reunión de lo que él denominaba una "junta magna" destinada a resolver los grandes problemas nacionales. Merece la pena señalar no sólo lo inviable de este proyecto político que podía ser considerado como una asamblea nacional parecida a la de la Dictadura, sino también su carácter poco propicio a conmociones políticas de tipo revolucionario. Ortega estaba a favor de una república que garantizara la modernización liberal, pero no era favorable a una república revolucionaria. 
El gran proyecto colectivo de Ortega fue la «Agrupación al Servicio de la República", creada en el mes de enero de 1931 y cuyo manifiesto fundacional data del mes siguiente, es decir de una fecha muy tardía. El proyecto sin embargo, había tenido una larga gestación pues, como narró Pérez de Ayala en la prensa argentina, la primera idea data del momento de la visita de los intelectuales a Barcelona, un año antes. Junto con Ortega, Pérez de Ayala y Marañón, tomaron parte en las primeras reuniones otros intelectuales como Jiménez de Asúa que representaban posiciones muy distintas y que luego desaparecieron del proyecto, al que, en cambio, se incorporaron otros como "Azorín» y Machado. En cualquier caso parece evidente tanto el éxito de la iniciativa, que llegó a congregar a 20.000 afiliados en tan sólo unas semanas, como la inspiración orteguiana del grupo. En efecto, las dos ideas fundamentales de la Agrupación fueron la necesidad de crear un Estado auténticamente nacional y la de llevar a cabo una profunda transformación de la vida pública.

Junto a estas actividades de talante más propiamente intelectual, Ortega se planteó también una labor de articulista político que le llevó a enzarzarse en polémicas con algunos de los más relevantes personajes que todavía le quedaban a la monarquía, como Romanones, Gabriel Maura - Cambó. La polémica sobre los "problemas concretos" con estos dos últimos demuestra una radical diferencia de criterio, al estar Ortega deseoso de un fundamental cambio en las instituciones antes de llevar a cabo cualquier planteamiento de esos problemas concretos en los que insistía Cambó. Esas polémicas contribuyen a explicar la llamada pérdida de $E / S o l$, es decir la alteración de su significado ideológico mediante la intervención directa de sus propietarios y la fundación del diario Crisol.

En esta tarea de modernización liberal del Estado español a Ortega le acompañaron algunos significados intelectuales, de los que tuvieron una especial presencia en los medios de comunicación dos: Pérez de Ayala y Marañón. El primero insistió por estas fechas en los valores cívicos del pueblo español, el papel instrumental de la república como reformadora de la vida nacional y la responsabilidad de los hombres de leyes como juristas y no meros abogados en ese proceso de transformación. En cuanto a Marañón, experimentó un cambio rapidísimo desde su identificación con Unamuno y con posiciones radicales, incluso socialistas, en la etapa dictatorial, a Ortega y la posición liberal que representaba en estos momentos de transición.

Nos queda hacer mención de dos grupos intelectuales que también tuvieron protagonismo por estas fechas aunque su relevancia fuera menor. Hubo, en primer lugar, un sector excéptico que recibió con reticencia la politización del momento. A veces se trataba de personas que siempre 
mostraron despego respecto de cualquier actuación en la vida pública, como es el caso de Baroja. Los artículos escritos por Jacinto Benavente en $A B C$ a partir de octubre de 1930 muestran su oposición a que los intelectuales jugaran un papel político de alguna significación en la España del momento, pero también son expresivos de que él mismo sufría el impacto del ambiente, pues persona tan conservadora como él no tuvo inconveniente en mostrarse partidario, en estas fechas, de un vago socialismo. Finalmente, Wenceslao Fernández Flórez encontró argumentos a favor de esta actitud escéptica en el hecho de que figurara al frente del republicanismo una persona de la que tanto había abominado por su condición de cacique como Alcalá Zamora.

Nos queda, finalmente, la posición de aquellos intelectuales que habían ido adoptando con el transcurso del tiempo una posición autoritaria mucho más consistente que la del propio Primo de Rivera. Me refiero a D'Ors y a Maeztu. En D'Ors la postura autoritaria resulta perceptible en la evocación de figuras de significación ideológica tradicionalista como, por ejemplo, Menéndez Pelayo y Donoso Cortés. La presencia de la aguda politización en la España del momento se hace manifiesta desde finales de 1930 , momento en que D'Ors dio a conocer su pensamiento político dándole la denominación de "Heliomaquia", es decir, lucha con el sol, refiriéndose al diario de Ortega. De ahí que frente al "Delenda est monarchia» del filósofo liberal, él proclame un «Delenda est barbaria». Profundamente despreciativo de la causa republicana D'Ors expresa su confianza en una monarquía autoritaria basada en el orden clásico. Algo parecida fue la posición de Maeztu, pero mucho más crispada en parte por sentirse aislado en el mundo intelectual y en parte también por su mayor colaboracionismo con la Dictadura de Primo de Rivera. Maeztu citó también a Ménendez Pelayo como el intelectual más representativo de una monarquía de autoridad y orden pero, sobre todo, se dedicó a atacar las tesis democráticas de los intelectuales adversarios, en Las doctrinas de Galán reveló su significación revolucionaria y en El gatillo y el disparo quiso mostrar la responsabilidad de aquellos profesionales y pensadores que alimentaban las tesis revolucionarias. Maeztu llegó a hablar de la constitución militar de la monarquía española de la Restauración, adelantándose así al tono militarista que tendría la extrema derecha de los años treinta. En el Maeztu iluminado y obseso de 1930 está ya el pensador de los años republicanos.

\section{CONCLUSIONES}

De esta rápida descripción de posiciones intelectuales se deriva como conclusión que las posturas conformistas o escépticas se convirtieron, en 
estos meses cruciales, en minoritarias. Incluso se podría añadir que el repudio del pasado fue generalizado, pues quienes seguian siendo monárquicos lo eran de una opción autoritaria.

Sin embargo, por mucho que los intelectuales se hubieran declarado muy mayoritariamente republicanos, no debe pensarse que esta adscripción tuviera un significado idéntico. La República significaba, antes de proclamarse, cosas muy diferentes para los intelectuales e incluso para cada grupo generacional. La generación mayor fue antiprimorriverista y antialfonsina más que republicana. Los más jóvenes fueron extremistas de izquierda o de derecha. Los miembros de la generación de 1914 resultaron los más dispuestos a una actuación colectiva en estos momentos, pero diferían esencialmente en el contenido de la misma, pues Ortega y Azaña veían un eventual régimen republicano desde unas ópticas no sólo distintas sino contrapuestas.

No tiene pues nada de extraño que en el futuro se cuarteara esta unanimidad republicana de los intelectuales. En estos meses se gestaron los enfrentamientos de 1931-1936. Incluso puede decirse que nacieron también los instrumentos para ese combate, puesto que en las revistas juveniles de izquierda se presagiaba lo que luego serían Leviathán y Cruz y Raya. 